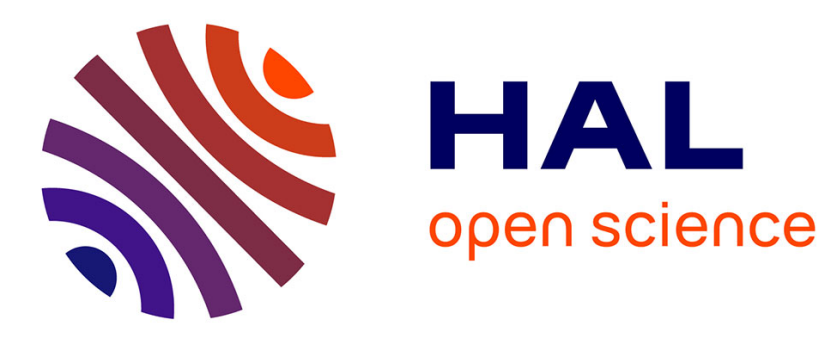

\title{
Uniaxial Compressive Behaviour of an Isotropic Graphite
}

\author{
A. Cosculluela, J. Farre
}

\section{To cite this version:}

A. Cosculluela, J. Farre. Uniaxial Compressive Behaviour of an Isotropic Graphite. Journal de Physique IV Proceedings, 1997, 07 (C3), pp.C3-471-C3-476. 10.1051/jp4:1997381 . jpa-00255538

\section{HAL Id: jpa-00255538 https://hal.science/jpa-00255538}

Submitted on 1 Jan 1997

HAL is a multi-disciplinary open access archive for the deposit and dissemination of scientific research documents, whether they are published or not. The documents may come from teaching and research institutions in France or abroad, or from public or private research centers.
L'archive ouverte pluridisciplinaire HAL, est destinée au dépôt et à la diffusion de documents scientifiques de niveau recherche, publiés ou non, émanant des établissements d'enseignement et de recherche français ou étrangers, des laboratoires publics ou privés. 


\title{
Uniaxial Compressive Behaviour of an Isotropic Graphite
}

\author{
A. Cosculluela and J. Farre*
}

CEA, BP. 16, 37260 Monts, France

*CEA, $21120 \mathrm{Is} /$ Tille, France

\begin{abstract}
Quasi static and dynamic uniaxial compression tests were performed on dumb-bell shaped specimen of a grade of graphite. The fracture of this kind of materiel is strain rate dependent. Indeed, we achieved two clearly different strengths. The graphite is less scattered compared to the ceramics. Its fracture seems brittle. However its mechanical behaviour is quasi linear elastic viscoplastic. At room temperature, this viscoplasticity can be explained because of the exhibition of two combined physical phenomenon : glide motions of dislocations and mainly growth of microcracks slowed down by internal frictions.
\end{abstract}

\begin{abstract}
Résumé. Nous avons effectué des caractérisations mécaniques quasi statiques et dynamiques en compression uniaxiale sur des éprouvettes de forme diabolo d'une nuance de graphite. La rupture est fortement dépendante de la vitesse de sollicitation. Le graphite est moins dispersif que les céramiques classiques. Son comportement à la rupture peut être qualifié de fragile. Cependant, sa réponse mécanique est de type élastique quasi linéaire viscoplastique. Cette viscoplasticité à temperature ambiante est due à quelques mouvements de dislocations mais surtout à la présence de nanofissures entre les plans graphitiques dont la propagation est freinée par des frottements internes.
\end{abstract}

\section{INTRODUCTION}

Polycrystalline graphites are structural materials used at high temperatures. The influence of the heat or the heating rate on the mechanical behaviour of this kind of materials have been studied for many years $[1,2$, 3]. We know that the fracture of graphite is brittle and its behaviour is an elastic plastic one $[4,5]$. $[6,7]$.

Some authors have carried out investigations to understand the deformation and fracture mechanisms

The purpose of this paper is to perform some uniaxial compressive tests at room temperature to exhibit the influence of the strain rate on the strength of a polycrystalline graphite.

First of all, we describe the material and the samples we tested. Then we give the characteristics of the experimental device. The results of the quasi static and dynamic tests are presented. They are analysed by mean of a Weibull statistical method. Then we discuss the results and we try to understand the mechanical behaviour (special focus will be done on the strain rate) of this graphite by means of other references, graphite monocrystal mechanical properties, optical and electron microscopy observations.

\section{MATERIAL STUDIED}

We selected a commercial synthetic graphite (EDM3) upon the recommendations of the producer (POCO) as to uniformity of density and properties in all directions. The graphitizing temperature supplied by the producer is $2800^{\circ} \mathrm{C}$. The figure 1 shows the porosity and the structural aspects of this material. The mean size of the pores is $5 \mu \mathrm{m}$. We will talk in the following about the difficulty to determine a grain size as done in the case of classical ceramics. 


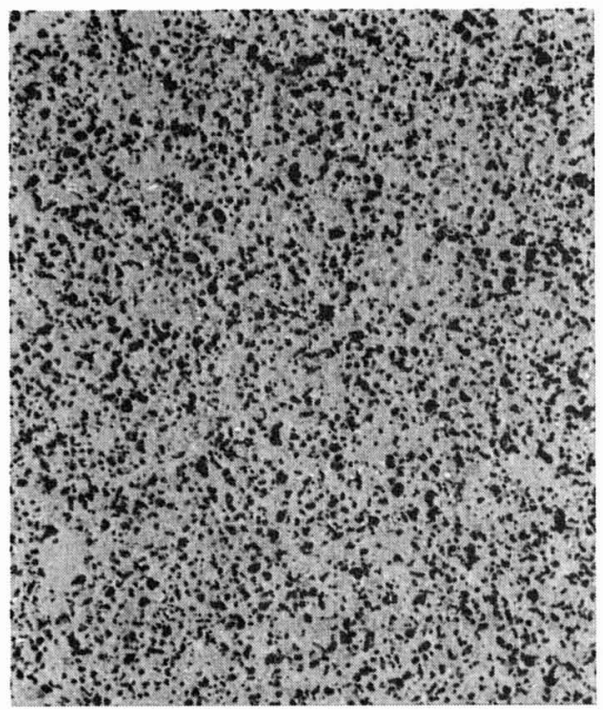

a) $-50 \mu \mathrm{m}$

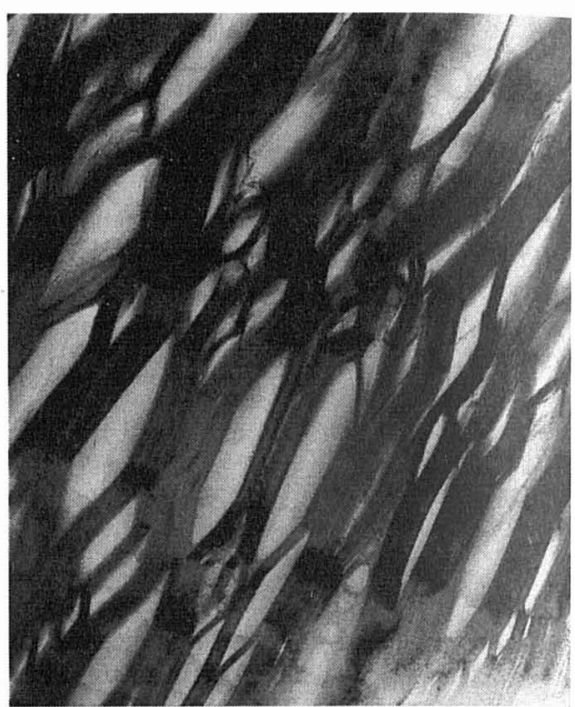

b ) $-0,1 \mu \mathrm{m}$

Figure 1 : Two scales of "microstructure" of the as-received material. a)optical microscopy. b)T.E.M.

\section{SAMPLES TESTED}

All the tests were performed on dumb-bell shaped specimen. This shape was calculated by a numerical and an analytical way $[8,9]$. The samples were machined with a computer-controlled engine. Biaxial gauges were glued on each sample so that axial and radial strains could be measured.

For each sample some characteristics were determined in the laboratory and the mean values are shown in the table I.

Table I : Mechanical characteristics of the samples

\begin{tabular}{|c|c|c|c|}
\hline Density & Elastic Moduli* & Young modulust & Poison ratio \\
& $\mathrm{E}_{11}=(11,4 \pm 0,02) \mathrm{GPa}$ & & \\
$(1,78 \pm 0,02) \mathrm{g} / \mathrm{cm}^{2}$ & $\mathrm{E}_{22}=(11,1 \pm 0,02) \mathrm{GPa}$ & $\mathrm{E}_{1}=(11,6 \pm 0,8) \mathrm{GPa}$ & $v=0,29 \pm 0,02$ \\
& $\mathrm{E}_{33}=(10,6 \pm 0,02) \mathrm{GPa}$ & & \\
\hline
\end{tabular}

* measured by mean of an ultrasonic waves propagation technique.

+ measured by gages.

We verified that all the samples could be considered uniform and isotropic.

\section{EXPERIMENTAL PROCEDURE}

\subsection{Experimental set-up}

Low strain rate compressive tests were achieved with a screw-driven testing machine Zwick of $200 \mathrm{kN}$ capability. The applied load was measured by a $20 \mathrm{kN}$ deflection-type dynamometer which is certified accurate to $\pm 5 \%$ of full scale. Tungsten carbide anvils were put on both sides of the samples during the tests. Also a special box was used to recover the fragments of the tested specimens.

High strain rate compressive tests were achieved with a Split Hopkinson Pressure Bars device described by others $[10,11]$. The input and output bars were made with a PER 72 refractory steel. Tungsten carbide anvils were put on both sides of the samples; within the experiences some soft-recovery tests were performed. 
The total length of the samples is $26 \mathrm{~mm}$, the length of the cylindrical part is $10 \mathrm{~mm}$. The two diameters of each sample are 10 and $6 \mathrm{~mm}$ (fig.2).

\subsection{A new analysis for SHPB}

We try to establish a new method to analyse the experimental pulses in the case of dumb-bell shaped specimen.

All the calculations associated with the SHPB are one-dimensional. The sample is supposed to be and to remain cylindrical shaped during the test. Its diameter $\varnothing_{0}$ and its length $L_{0}$ must be taken into account.

There is no particular problem when ductile materials are tested; in the case of brittle materials, with very low fracture strain, we use a computer code "DAVID" developed in the Ecole Polytechnique [12] by G. GARY to verify that the forces on both sides of the sample are equal at the time of the fracture.

In the case of dumb-bell shaped specimen we suggest to calculate an equivalent length of the sample too. We meshed the sample as shown in the figure 2 .

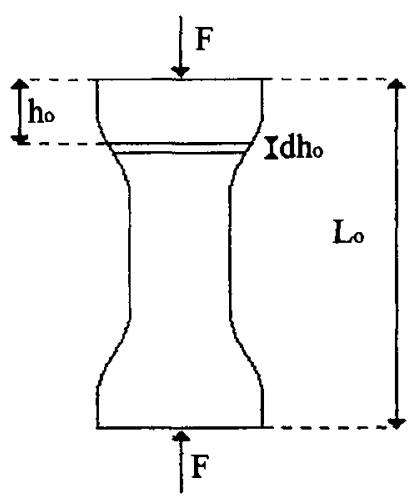

Figure 2 :Dumb-bell shaped specimen.

$$
\begin{aligned}
& \sigma\left(\mathrm{h}_{\mathrm{o}}\right)=\mathrm{E} \frac{\Delta \mathrm{dh}_{\mathrm{o}}}{\mathrm{dh}_{\mathrm{o}}} \\
& \sigma\left(\mathrm{h}_{\mathrm{o}}\right)=\frac{\mathrm{F}}{\mathrm{S}\left(\mathrm{h}_{\mathrm{o}}\right)} \\
& \frac{\mathrm{F}}{\mathrm{S}\left(\mathrm{h}_{\mathrm{o}}\right)} \mathrm{dh} \mathrm{o}_{\mathrm{o}}=\mathrm{E} \Delta \mathrm{dh}_{\mathrm{o}} \\
& \mathrm{F} \int_{0}^{L_{\mathrm{o}}} \frac{1}{\mathrm{~S}\left(\mathrm{~h}_{\mathrm{o}}\right)} d \mathrm{~d}_{\mathrm{o}}=\mathrm{E} \Delta \mathrm{l}
\end{aligned}
$$

where $\Delta \mathrm{l}$ is the total strain of the dumb-bell shaped sample. Then

$$
F \int_{0}^{L_{o}} \frac{1}{\pi R^{2}\left(h_{o}\right)} d h_{0}=E \Delta l
$$

If

$$
\mathrm{K}=\int_{0}^{L_{\mathrm{o}}} \frac{1}{\pi \mathrm{R}^{2}\left(\mathrm{~h}_{\mathrm{o}}\right)} d \mathrm{~h}_{\mathrm{o}}
$$

The equation (5) can be written

$$
\mathrm{FK}=\mathrm{E} \Delta \mathrm{l}
$$

And

$$
\frac{\mathrm{F}}{\mathrm{S}_{\mathrm{o}}} \frac{\mathrm{KS} \mathrm{S}_{\mathrm{o}}}{\mathrm{L}_{\mathrm{o}}}=\mathrm{E} \frac{\Delta \mathrm{l}}{\mathrm{L}_{\mathrm{o}}}
$$

For the dumb-bell shaped samples used in this study $\frac{\mathrm{K} \mathrm{S}_{\mathrm{o}}}{\mathrm{L}_{\mathrm{o}}}=0,63$.

So, if we want to use DAVID code, the real total length $26 \mathrm{~mm}$ should be remove by $16,4 \mathrm{~mm}$.

The figure 3 shows the improvement of the knowledge of the real strain. The figure present the axialdeformation as a function of time obtained thanks to strain gauges and to new analysis. This analysis allow to obtain $\sigma-\varepsilon$ curves until fracture, even if the strain gauges are unglued. We suppose that material velocity of the input bar is constant during the test. 
Are the gauges still essential? One have to notice that for the moment, the good determination of the time to fracture remains difficult. Moreover the radial strain can not be known without gauges. However, in the case of this material, it was difficult to measure all the strains until the fracture of the samples because of the plastic behavior and plastic strains induced as presented in the following.

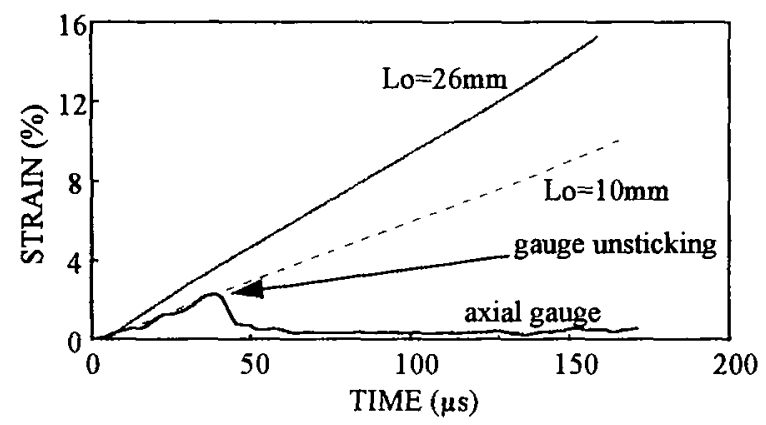

Figure 3 :Results obtained by a new analysis of a Split Hopkinson Pressure Bars test.

\section{RESULTS}

\subsection{Elastic plastic mechanical behaviour}

First, in order to estimate the plastic behavior of this polycristalline graphites we tested the samples in loading-unloading conditions at low strain-rate $\left(\dot{\varepsilon}=10^{-4} \mathrm{~s}^{-1}\right.$ ) (figure 4).

The loading-unloading curves show a quasi linear elastic part if $\sigma<100 \mathrm{MPa}$ and a plastic mechanical behavior until the fracture of the sample.

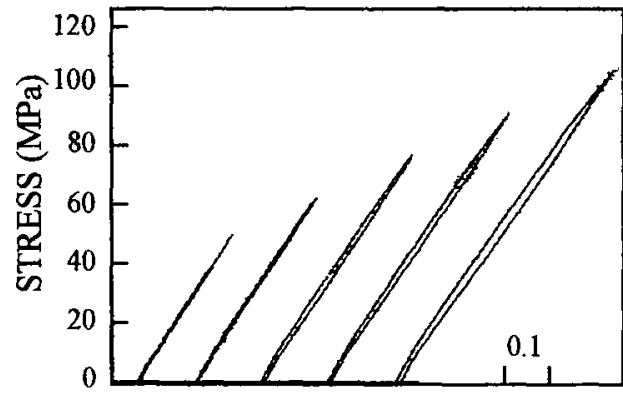

STRAIN (\%)

Figure 4 : Loading-unloading compressive tests on dumb-bell shaped specimen.

\subsection{Results of quasi static tests}

For those tests strain gauges detachment prevent us to obtain $\sigma-\varepsilon$ curves until fracture. The fracture strain $(4,5 \%)$ is estimated thanks to the screw-driven testing machine. The mean fracture stress obtained during compressive tests at low strain-rate $\left(\dot{E}=10^{-4} \mathrm{~s}^{-1}\right)$ is $144 \mathrm{MPa}$. This result is completed by the following Weibull statistical analysis. 


\subsection{Results of dynamic tests}

First, for dynamic tests, we verify that the forces on both sides of the sample are equal. The DAVID software indicate that the equilibrium is obtain after about $15 \mu \mathrm{s}$. Fracture occurs after about $120 \mu \mathrm{s}$.

The figure 5 presents a $(\sigma, \varepsilon)$ curve given by the new analysis. Its difficult to exhibit,as for others materials, an accurate $(\sigma, \varepsilon)$ curve when the strain is lower than $2 \%$.

The value of the mean fracture stress is about $185 \mathrm{MPa}$ and the fracture strain about $7,5 \%$. The fracture is defined when stress is maximum. Mean strain rate value is $500 \mathrm{~s}^{-1}$.

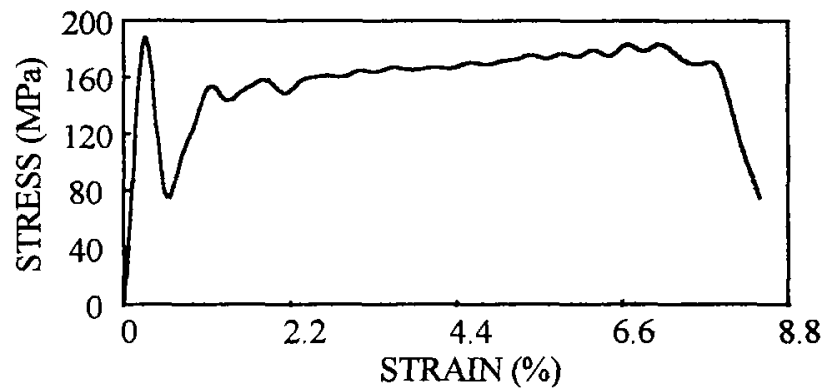

Figure 5 :Dynamical behavior of a quasi isotropic graphite under uniaxial compression

The Weibull statistical method used is a two parameters statistic where the classical value $\mathrm{V}$ of the volume of sample is taken at 1 in order to simplify the results. Then, the probability Pr associated to the fracture of a sample above $\sigma_{\mathrm{r}}$ is :

$$
P_{r}=1-\exp \left[-\left(\frac{\sigma_{r}}{\sigma_{u}}\right)^{m}\right]
$$

where $\mathrm{m}$ is related to the dispersion and $\sigma_{\mathrm{u}}$ is a normalization factor.

We give also the confidence interval at $50 \%$. With the technique of the Maximum Probability the results are presented in the following table :

Table II : Results of the Weibull statistic applied to each kind of tests.

\begin{tabular}{|c|c|c|}
\hline Test & $\mathrm{m}$ & $\sigma_{\mathrm{u}}(\mathrm{MPa})$ \\
\hline Quasi static & $30,5[23 ; 38]$ & $143,1[141,7 ; 144,5]$ \\
\hline Dynamic & $35,5[27 ; 45]$ & $185,8[184,3 ; 187,3]$ \\
\hline
\end{tabular}

Mann and Kolmogorov tests prove at a probability value higher than $80 \%$ that the hypothesis of these statistics can not be turned down.

\section{DISCUSSION}

The mechanical behaviour of this graphite is strain rate dependant (table II) as shown by others [4, 13]. The fracture looks brittle under uniaxial compression. This material is less scattered (table II) compared to classical ceramics $(m=5)$ [9]. The Weibul moduli are strain rate independent.

The loading-unloading curves show that the elastic part of the mechanical behaviour is short. But the plastic strain measured before the fracture are quite small. So that we have to understand why the plasticity occurs so early in the deformation process? And although the elastic energy is low, why this process lead so quickly to the fracture of the sample? 
The graphite grains observed by optical microscopy can be considered as a group of coke particles and binder. They can be defined as a scale of an optic anisotropy. But, by T.E.M., we can take inti account the graphite crystallites. The graphite crystal is hexagonal. Even if the samples are randomly isotropic (optical scale), the mechanical properties of a crystal are anisotropic. The low shear stiffness (250 $\mathrm{MPa})[1,5]$ between the basal planes (linked by Van der Waals forces) of the crystallites allows the coke particles themselves to deform by shear. Indeed the coke particles exhibits a long range order with the $a$-axis of the crystallites.

Various kinds of dislocations in graphite crystallites have been established [6]. They are mainly due to the contribution of thermal stresses caused by the very anisotropic expansion of crystallites during the graphitization process. But at room temperature it seems that the main phenomenon is the propagation (mode II) of micropores (fig. Ib) between basal planes. The internal friction during the propagation by shearing can explain the viscous effects

The fracture of the graphite depend, of course, strongly on the microstructure as shown by others [4]. The propagation of the cracks follows the basal planes (fig. $1 \mathrm{~b}$ ). The fracture is reliable to the macroporosity measured from optical microscopy [13]. But we did not demonstrate exactly what is the influence of the microporosity on the strength of graphite. We only exhibit that, concerning fracture stress, the weakest defaults are the greatest pores [14]

\section{CONCLUSION}

We did show the influence of the strain rate on the mechanical behaviour of an isotropic graphite. We exhibit the importance of the observation scale to understand the relationships between the structural parameters of the material and the mechanical behaviour. The microporosity explain the plasticity and the modelling of the macroporosity can provide the fracture stress.

\section{Acknowledgement}

The authors wish to thank Elisabeth Patron, the young research scientists and the technical assistants who contributed to this work.

\section{References}

[1]Jenkins J.M., Carbon, 3 (1964) 521-541.

[2] Oberlin A., Carbon, 22 (1966) 521-541

[3]Smith M.C., Carbon, 1 (1964) 529-543.

[4]Rappeneau J. et al., Carbon, 3 (1966) 407-420.

[5] Losty H.H.W., " Modern aspects of graphite technology », L.C.F. Blackman, London 1970 p 201-221

[6] Tsuzuku T., "Dislocations in graphite crystals », Third Biennal Carbon Conference, Pergamon Press, Oxford, 1958 , p. $433-450$

[7]Allard B. et al., Carbon, 29 (1991) 457-468.

[8] Cosculluela A., Ph.D Thesis - Université de Bordeaux I - 1992

[9] Lamaison M., Ph.D Thesis - Ecole Nationale Supérieure des Arts et Metiers - 1997

[10]Chen W., Dymat Journal, 1 (1994) 193-210.

[11] Bacon C., Ph.D Thesis - Université de Bordeaux I - 1993

[12] Zhao H., Ph.D Thesis - Ecole Nationale des Ponts et Chaussées - 1992

[13] Diefendorf R.J., "The effect of atmosphere on the strength of graphite", Fourth Biennal Carbon Conference, Pergamon Press, Oxford, 1960, p. 433-450

[14] Farré J., « Relation entre la porosité et les propriétés mécaniques des graphites isotropes - Approche Mécanique de la Rupture », Technical report, CEA/B3/DETN/MA nº 694-1995. 